\title{
De Re and De Dicto Explanation of Action
}

\section{Sean Crawford}

University of Manchester

That de dicto or "opaque" ascriptions of thought explain actions is a very familiar idea and virtually beyond dispute. The idea that de re or "transparent" ascriptions of thought are explanatory of action, however, is not at all familiar and has mostly been denied by philosophers. ${ }^{1}$ But those who deny any psychological explanatory role to de re ascriptions have been looking in the wrong place. They have mistakenly aligned $d e$ re explanation with de dicto explanation and then found the former at fault for not living up to the demands naturally placed only on the latter. The truth is that de re ascriptions of thought answer to explanatory ends very different from those of $d e$ dicto ascriptions and when this is brought out the essentially perspectival nature of thought ascription and action explanation is revealed. In this paper I explore the relation between thought ascription and the explanation of action and develop an account according to which de dicto ascriptions and de re ascriptions each form the basis for two different kinds of action explanations, rationalizing and nonrationalizing ones. In the first section I explain the Quinean account of thought ascriptions that I adopt. Though Quine's views here are well known, they are not well understood, and I highlight important aspects of his thought on this issue that have largely been ignored. These aspects are, first, a principle about the connection between language and though and, second, the nature of the closely related

\footnotetext{
${ }^{1}$ See, e.g., Schiffer (1978), Fodor (1980), Dennett (1982), Baker (1982), Lycan (1985), Carruthers (1988), and Boghossian (1994).
} 
"assumption of rationality" governing thought ascription and action explanation. In the second section, I explain how the two types of ascription, so understood, operate in rationalizing and non-rationalizing psychological explanations of action. In the third, I use the account of de re explanation developed to criticize a rival "two-factor" or "dual-component" view of explanation. The criticism deepens our understanding of de re explanation.

\section{Thought ascription}

In order to explain and justify the account of attitude ascription that I shall employ, I need to turn back to Quine's seminal 1956 discussion of the matter in 'Quantifiers and Propositional Attitudes'. ${ }^{2}$ As the reader will no doubt recall, Quine's overall theme is how to symbolise two readings of ambiguous natural language sentences containing psychological verbs — such as 'I want a sloop' and 'Ralph believes that someone is a spy' - using an extensional and first-order logic in which the quantifiers receive their standard objectual interpretation. The latter sentence, for example, could mean either 'Ralph believes there are spies' or 'Someone is believed by Ralph to be a spy' and the former either 'I want relief from slooplessness', as Quine famously puts it, or 'There is a particular sloop I want'. Quine's question is: Does elementary logic contain the resources for representing these two kinds of reports?

\subsection{De re and de dicto ascriptions of thought}

The obvious first move is to represent the two readings as follows:

(1) Ralph believes that $(\exists x)(x$ is a spy)

\footnotetext{
2 See also chapters four and five of Word and Object (Quine, 1960) and 'Intensions Revisited' (1977). I develop Quine's account of attitude ascriptions, and defend it against objections, in much more detail in Crawford (2008), on which the discussion in section 1 is based.
} 
(2) $(\exists x)($ Ralph believes that $x$ is a spy).

Quine notes, however, that (2) involves 'quantifying into a propositional attitude idiom from outside', which, he claims, 'is a dubious business, as may be seen from the following example' (p.185). The example is, of course, the famous story of Ralph who has seen a suspicious character in a brown hat who he thinks is a spy. Ralph has also seen a grey haired man at the beach who he thinks is a pillar of the community and who is known to him as Bernard J. Ortcutt. Unbeknownst to Ralph, Ortcutt is both pillar and spy. Given this identity, Quine then asks whether we can say of this man, Bernard J. Ortcutt, that Ralph believes him to be a spy. If we answer affirmatively, Quine says, then we must accept conjunctions of the following type:

LTD $w$ sincerely denies '...' and believes that ...

in which the blanks are filled by the same sentence ('LTD' for 'Language-Thought Disparity'). This is because Ralph sincerely denies that the sentence 'Ortcutt is a spy' is true. But LTD-type conjunctions are unacceptable, thinks Quine - though he gives no reason for thinking this. This crucial premise of Quine's - the ban on LTD-type conjunctions - is rarely noticed in any of the subsequent discussion of Quine's argument; it is in fact extremely important, however, and will play a central role in the nature of one kind of thought ascription and the kind of psychological explanation that it makes available. Following through this line of thought, that LTD-type conjunctions are to be barred, we end up endorsing the following:

(3) Ralph believes that the man in the brown hat is a spy

(4) Ralph does not believe that the man seen at the beach is a spy. and thus embracing the referential opacity of the context 'believes that ...'. The context is referentially opaque because the singular term position is not "purely referential," that is, does not function simply to introduce an object for predication. 
Quine takes substitution of coreferential singular terms salva veritate as the criterion

for whether a term position is purely referential (1960, p. 142). Referentially

transparent contexts are ones in which all singular term positions are purely

referential. Quine assumes that (3) and (4) describe a relation between Ralph and

Ortcutt only if the term positions in the complement clauses ("the man in the brown

hat' and 'the man seen at the beach') are purely referential. Since they are not purely

referential, because substitution salva veritate fails, he concludes that (3) and (4)

'cease to affirm any relationship between Ralph and any man at all' (p. 185). ${ }^{3}$ It

follows from this that 'It then becomes improper to quantify as in [(2)]' (pp. 185-6).

Quine initially suggests that we resolve the problem of quantifying in by positing

two different senses of belief, 'belief ${ }_{1}$, which disallows [LTD], and belief $_{2}$, which

tolerates [LTD] and makes sense of [2]', but then rejects the approach, offering

instead a 'more suggestive treatment' (p. 186) that operates with a single sense of

belief, belief ${ }_{1}$, according to which LTD-type conjunctions are 'disallowed' ${ }^{4}$ This is

utterly crucial: the univocal sense of 'belief' is, for Quine, partly defined by the

\footnotetext{
${ }^{3}$ The move from the failure of substitution to the non-affirmation of any relationship between Ralph and any man appears to be a non sequitur. In chapter 4 of Word and Object, Quine is more cautious. Failure of substitution into a subsentential position does not necessarily indicate that the containing sentence ceases to affirm any relationship at all between person (e.g., Ralph) and object (e.g., Ortcutt); rather, it indicates that the singular term-taking position in the sentence is 'not purely referential', where impure referentiality admits of degrees, in which some sentences have 'more bearing' on their objects than others $(1960$, p. 142). (The point that occurrences of singular terms within psychological contexts can serve both to relate the thinker to an object and characterise how he thinks of that object was later noticed by a number of authors, Loar (1972) among them. Discussion of and references to this 'double duty' view of singular terms can be found in Burge (1977). So Quine's well-known thesis that 'a position that resists substitutivity of identity cannot meaningfully be quantified' (1986a, p. 291), as applied to attitude ascriptions, cannot be defended on the grounds that the substitution-resistant position within a sentence indicates that that sentence does not affirm a relationship between a person and an object. However, there are other good reasons for thinking that there is a tension in the case of attitude ascription between failure of substitution and quantifying in. As Graeme Forbes (1996) has argued, 'the cautious version of [Quine's thesis] claims only that there is a certain range of cases of substitution failure that involve a mechanism incompatible with quantifying in' and that 'The puzzle is that although attitude ascriptions seem on general grounds to belong to this range ... we have the particular example of [(2)] to indicate otherwise' (p. 338).

${ }^{4}$ It is important not to confuse the two senses of belief posited by the rejected proposal, which is sustained for all of one small paragraph, with Quine's notional and relational senses of belief. This conflation is very widespread in discussions of Quine's argument. I try to clear up the confusion in Crawford (2008).
} 
impossibility of LTD-type conjunctions. What it is to have a belief with a content that is specified by a certain sentence is, in part, to accept that sentence (if one understands it). If one does not accept the sentence in question one cannot have a belief the content of which is specified by that sentence. On this proposal, psychological verbs are treated as multigrade predicates, not only capable of taking a arbitrary number of arguments - like '.. are parallel', ‘ $\ldots$ are colleagues', ‘.. live together' - but also capable of taking arguments of different kinds, namely, thinkers, particular objects, and 'intensions' (i.e., properties, relations, and propositions). ${ }^{5}$ This solution to the problem essentially involves providing logical forms for attitude ascriptions in which the singular term in the complement clause is moved outside the substitution-resistant position and into a purely referential position where it is thus open to both substitution and quantification. 'Believes', for example, always takes a subject and an intension as arguments and it is the names of the intensions only that are always referentially opaque, that is, that admit neither substitution nor quantification. The single predicate 'belief' (the original 'belief,') is then taken as having dyadic, triadic, tetradic and higher degree cases. Dyadic belief relates the believer to a proposition - for example, 'Ralph believes that Ortcutt is a spy' (which, given the story, is false). The triadic, tetradic, and higher degrees relate a believer to a property or relation and an object, where the singular term referring to the object is in referential position. On this account a de dicto ascription of belief is simply an ascription of the dyadic predicate 'believes' to a believer and an intension (proposition) and a de re ascription is an ascription of the triadic or tetradic or any higher degree predicate 'believes' (Quine

\footnotetext{
5 See also Quine 1960, $\$ 35$ and 1977. The idea is in effect a reworking of Russell's (1910) 'multiple relation' theory of judgement, with - contrary to the whole point of Russell's theory - the addition of propositions as possible intentional relata.

${ }^{6}$ Quine's proposal here is the proto-type for many later accounts, such as Wallace (1972), Loar (1972), Burge $(1977,1982)$ and Forbes (1996).
} 
1977) to a believer, a number $n$ of other individuals and an $n$-ary intension (property or relation), where $n \geq 1$.

\subsection{Ways of thinking, linguistic competence and the "assumption of rationality"}

It is clear that a de dicto ascription of belief is supposed to tell us the way that a believer conceives of the object of his belief. We know from Quine's story about Ralph and Ortcutt that although Ortcutt $=$ the $\operatorname{man}$ in the brown hat $=$ the man at the beach, Ralph is unaware of this fact so that if queried he would accept the truth of the sentence:

(5) The man in the brown hat is a spy

but deny the truth of the sentence:

(6) The man at the beach is a spy,

if he understood them. It is Ralph's different attitudes towards these two sentences, together with the ban on LTD conjunctions, that determines the truth of the de dicto attribution to Ralph of the belief that the man in the brown hat is a spy and the falsity of the de dicto attribution to him of the belief that the man at the beach is a spy. A singular term falling within the scope of dyadic 'believes' — that is, in Quine's parlance, falling within the boundary marked by the name of the intension - does not merely introduce an object for predication; it also gives the way the believer, or more generally, the "attitudinist" (as Quine calls him), thinks of the object. The way the attitudinist thinks of the object is determined by which sentences about the object he will accept, deny, and remain agnostic about, in accordance with the ban on LTD situations. ${ }^{7}$ Since on the de re reading the singular term referring to Ortcutt falls

\footnotetext{
${ }^{7}$ This linguistic criterion is present in Q\&PA but it is more explicit in Word and Object; see especially pp. 145, 148 of Quine, 1960. A different and very interesting account of idea that de dicto attributions implicitly contain attributions of beliefs about language_-"de lingua beliefs" - is given by Fiengo and
} 
outside the scope of triadic 'believes', its sole function is to introduce an object for predication and so it does not give the way Ralph thinks of Ortcutt. Ralph has, in a sense, inconsistent beliefs, for the following de re reports are true:

(7) Ortcutt is believed by Ralph to be a spy

(8) Ortcutt is believed by Ralph not to be a spy.

(7) and (8) are, as Quine puts it in Q\&PA, 'near-contraries'. This is not to charge Ralph with irrationality, however, for given Quine's story about Ralph's cognitive life vis-à-vis Ortcutt, his predicament makes perfect epistemological sense and is entirely rational. In light of this we should not look on (7) and (8) as implying:

(9) Ortcutt is believed by Ralph to be a spy and not to be a spy. ${ }^{8}$

Ralph does not believe Ortcutt to have the impossible property of being and not being a spy. Consider now the simultaneous truth of the following de dicto ascriptions:

(10) Ralph believes that Ortcutt is a spy

(11) Ralph believes that Ortcutt is not a spy.

Whereas (7) and (8) do not imply (9), it is arguable that (10) and (11) do imply, or at least strongly suggest, that

(12) Ralph believes that Ortcutt is a spy and is not a spy.

The reason why (10) and (11) imply (12) is that it is arguable that quite generally $S$ 's believing that $a$ is $F$ and $S$ 's believing that $a$ is $G$ imply that $S$ believes that $a$ is $F$ and $G$. The reason for this is that the truth of the de dicto ascriptions, $S$ believes that $a$ is $F$ and $S$ believes that $a$ is $G$, is a sufficient condition for $S$ 's accepting (understandingly) the sentences $\mathrm{a} a$ is $\mathrm{F}$ and $\mathrm{a}$ a is $\mathrm{G} \cdot$ This is enshrined in the ban on LTD conjunctions. Now, if $S$ accepts - or is disposed to accept - the sentences ‘a is $\mathrm{F}$ and a is $\mathrm{G}$ ' then it is

May (2006). Although their account places central emphasis on the subjects' beliefs about the semantic values of sub-sentential expressions, particular proper names, I believe their account delivers essentially the same results as the Quinean one presented here.

${ }^{8}$ Quine, 1956, pp. 188-89 and 1960,p. 148. 
hard to see how $S$ could fail to accept-or fail to be disposed to accept-the sentence a is $\mathrm{F}$ and $\mathrm{G}$, after due consideration of it, so long as $S$ understands both occurrences of a as referring to the same thing and is a competent speaker of the language (understands, for example, what 'and' means). Indeed, it is partly constitutive of being a competent speaker of English that one accept ' $\mathrm{a}$ is $\mathrm{F}$ and $\mathrm{G}$ ' when one accepts ' $a$ is $F$ and $a$ is $\mathrm{G}-$ at least when one is paying attention and the sentences are not too long and complicated. Of course, it is also constitutive of being a competent speaker of English that one not accept sentences that are simple formal contradictions when one understands them to be so. Since, according to the ban on LTD conjunctions, it is necessary for the truth of (12) that Ralph accept the sentence:

(13) Ortcutt is a spy and is not a spy, it appears that we must say that Ralph is not a competent speaker of English. It is pretty clear that Ralph cannot be said to understand (13) as we do and accept it; for understanding what (13) says is, at least in part, to realise that it cannot (literally) be true. So it appears that we can have no grounds on which to claim that (12) is true.

This fact drives home the point we are converging on: the content clauses of $d e$ dicto ascriptions of belief, unlike those of de re ascriptions, are subject to the basic principles of logic and rationality. Here is not the place to enunciate the principles jointly constituting the so-called "assumption of rationality" governing the de dicto ascription of beliefs; the principles are a matter of debate that we cannot pause to enter here. However, we can, I think, safely assume that the principles include the basic logico-syntactic rules of consistency such as conjunction introduction, modus ponens, and non-contradiction. There is nothing particularly mysterious about the "assumption of rationality" governing de dicto ascriptions of belief; for the assumption derives from the fact that speaking logically is part of what it is to speak 
competently. As Quine says, 'we learn logic in learning language' (1986b, p. 100).

Since the only de dicto ascriptions of belief that can be true of an individual are those whose content clauses correspond to the sentences he accepts qua competent speaker of a language, and being a competent speaker of a language means by and large abiding by the basic rules of logic, the only de dicto ascriptions that can be true of an individual are those whose content clauses conform to the basic rules of logic. ${ }^{9}$ At least there should be no more mystery here than there is already mystery in what is involved in being a competent speaker of a language. Whatever the exact relation between logical ability and mastery of the grammar of natural language is, it cannot be denied that competent speakers of a language by definition for the most part speak logically; it is this latter fact from which the assumption of rationality governing the de dicto ascription of beliefs derives. ${ }^{10}$

\subsection{Ontological perspective}

The de dicto/de re distinction is not only a distinction between ascriptions which are, and ascriptions which are not, constrained by principles of rationality; it is also a distinction between two different ontological perspectives, the ascriber's and the ascribee's (cf. Brandom 1998). When we give de dicto reports, we empathize with our

\footnotetext{
${ }^{9}$ To the best of my knowledge, Tomkow (1992) was the first to argue this explicitly, and I first learned of it in seminars he delivered at Dalhousie University in 1992.

10 Kripke's (1979) stories about Pierre and Peter are not counter examples to the claim that the "constraints of reason" prohibit the joint truth of (10) and (11). For, to take the second case, it is part of Kripke's story that Peter takes the two occurrences of the proper name 'Paderewski' in the two sentences he accepts ('Paderewski had musical talent' and 'Paderewski did not have musical talent') to refer to different men; that is, he understands the two occurrences of 'Paderewski' differently. In contrast, it is part of Quine's story that in the situation imagined in which (10) and (11) are both true, Ralph understands the two occurrences of 'Ortcutt' in the two sentences he accepts ('Ortcutt is a spy' and 'Ortcutt is not a spy') to refer to one and the same man. This is why Ralph would be irrational while Peter is not. In the useful “de lingua belief” framework of Fiengo and May's (2006, chapter 2) account of de dicto attributions, we can say that whereas Ralph believes one 'Ortcutt'-Assignment, Peter believes two 'Paderewski'-Assignments; that is, both occurrences of the co-spelled expression 'Ortcutt' are co-valued by Ralph, and are therefore different occurrences of the same expression, whereas the two occurrences of the co-spelled expression 'Paderewski' are not co-valued by Peter and so are occurrences of different co-spelled expressions. Charges of irrationality concern de dicto ascriptions of belief in contrary contents to a subject where the subject believes only one Assignment.
} 
subject (as Quine says) by pretending to adopt his ontology; when we give a de re report we stick to our own ontology, saying what we take to be the thinker's object of thought. When, in giving a de dicto report, we pretend to adopt the attitudinist's ontology, we do two things: we act as if there were an object for the attitudinist's belief to be about and we describe that object from the attitudinist's perspective. With a de re ascription we revert to our own ontology, in the sense if we have reason to believe that there is no object for the attitudinist's thought to be about we forego the possibility of a de re ascription; and if there is such an object we describe the object from our point of view, which may involve attributing properties to it that the attitudinist is not aware that it possesses.

\section{The psychological explanation of action}

This difference in perspective is also present in the case of action. Action can be described from the agent's point of view or from an external observer's point of view that may not be shared by the agent. The former is a case of intentional action and the latter a case of action simplicter. I shall now argue that de dicto ascriptions of thoughts are required to explain intentional actions whereas de re ascriptions are required to explain actions simpliciter.

\subsection{Action and intentional action; or, doings and tryings}

There is a familiar distinction between actions and intentional actions. As Davidson (1980) has argued persuasively, following G.E.M. Anscombe's lead, an intentional action is not an event distinct from an action that is not intentional; rather, to say of an action that it is intentional is to say that there is some description of it under which it is intentional. Abelard's action of marrying Heloise and his action of doing something 
that would bring about his own castration are the same event. What we have are two different descriptions of one and the same event, the latter a description under which Abelard's action is intentional, the former a description under which it is not intentional. We may want to explain Abelard's action under a description under which it is intentional or we may want to explain Abelard's action under a description under which it is not intentional. In the former case, the explanandum sentence might be: Abelard's marrying of Heloise; in the latter it might be: Abelard's bringing about his own castration. A natural way to describe the difference between action and intentional action is to say that the former is what an agent is doing while the latter is what the agent is trying to do. Picturing ourselves at the wedding ceremony we can imagine saying that what Abelard is trying to do is marry Heloise and that one of the things he does, unbeknown to him, is bring about his own castration. Abelard's marrying Heloise is an intentional action because it is something he is trying to do; his bringing about his own castration is not an intentional action because it is (most definitely) not something he is trying to do (though, alas, he did it all the same). To avoid unnecessary circumlocutions and general prolixity, I shall speak of the psychological explanation of tryings, by which I shall simply mean a psychological explanation of an agent's action under a description that is necessarily an intentional one. And I shall speak of psychological explanations of doings, by which I shall mean the psychological explanation of an agent's action under a description that is not necessarily intentional (though it may be).

\subsection{Psychological explanation and perspective}

One of the main theses of the above discussion of de re and de dicto attributions is that the former describe the object of the subject's thought from the ascriber's point of 
view whereas the latter describe it from the subject's point of view. The de dicto ascription that Ralph believes that the man in the brown hat is a spy specify things from Ralph's point of view; he would, after all, give the nod to the sentence 'The man in the brown hat is a spy'. The de re ascription that Ortcutt (or the man at the beach) is believed by Ralph to be a spy specifies things from the point of view of the ascriber; though the de re ascription is true Ralph would not believe the sentences 'Ortcutt is a spy' and 'The man at the beach is a spy' to be true. A psychological explanation of an agent's intentional action, a trying, is an explanation whose point is to show that the action was reasonable from the agent's point of view. Davidson (1980) calls these ubiquitous explanations rationalisations. In order to so rationalise a trying we need to specify the agent's beliefs, desires, and intentions in a way that the agent would acknowledge as what he believes, desires, or intends. Since it is $d e$ dicto ascriptions that specify things from the agent's point of view, that is, in a way that the agent would acknowledge as the way he is thinking of things, it is de dicto ascriptions that are required to rationalise intentional actions or tryings. Why is Oedipus marrying Jocasta? Because he wants to accept the gratitude of the Thebans for solving the riddle of the Sphinx and believes that by marrying Jocasta he will achieve that end. But, as Davidson (1971a) has emphasised, our tryings have consequences of which we may or may not be aware, and because of this can be redescribed in terms of those consequences-even if those consequences are unintended. Since Jocasta is Oedipus's mother, his trying can be "re-described" as his marrying his mother. So marrying his mother is something that Oedipus does; it is an action of his and not merely a bunch of involuntary movements of his body and larynx. A psychological explanation for an action that is not intentional, a doing, is not an explanation whose point is to show that the action was reasonable from the 
agent's point of view. Indeed, since Oedipus does not have any reasons for marrying his mother (on the contrary!) the kind of psychological explanation that we give of Oedipus's marrying his mother cannot be a rationalising one. Rather, the point of such an explanation is to explain what actually happened from a non-Oedipal perspective; to explain why Oedipus's trying had the unintended consequence (as described from our perspective qua explainers or ascribers) that it did. Why on Earth did Oedipus end up marrying his own mother? Because he wanted to please the Thebans and (unfortunately) believed, of his mother, that marrying her would please the Thebans. Since the point of a psychological explanation of an agent's doing is to explain what actually happened as described from the point of view of the ascriber-that is, what was done according to the ascriber, whether or not the thing done under that description was intended by the agent - the explanans for such an explanation must include a de re ascription linking the agent's thoughts to the unintended consequence that is the explanandum. What explains Oedipus's marrying his mother is in part the tragic fact that it was his mother whom he believed his marrying would please the Thebans.

Since the singular term designating the object acted upon in the statement of a trying occurs in non-referential position inside the scope of the agent's attitude, we can say that tryings are the behavioural or actional counterparts to de dicto ascriptions of thoughts; whereas, since the singular term designating the object acted upon in a statement of a doing occurs in referential position outside the scope of the agent's attitude, we can say that doings are the behavioural or actional counterparts to de re ascriptions of thoughts (cf. Brandom 1998, ch8). Intentional actions, that is, tryings, are in this sense a species of propositional attitude (cf. Peaocke 1981); while actions simpliciter, doings, are not. It is because rationalisations of tryings must give the way 
agents' conceive of things that they must employ de dicto ascriptions. Since de dicto ascriptions are constrained by principles of rationality, they are naturally suited to explain, that is, rationalize, intentional actions. Since a doing is not necessarily something an agent intends to do, but is rather a consequence of what an agent tries to do, as that is determined by the ascriber, its explanation is a non-rationalizing one that involves de re ascriptions. As de re ascriptions are not bound by principles of rationality, they are suited to the non-rationalizing explanation of actions simpliciter, tryings.

Suppose that Ralph subsequently meets Ortcutt at a party and recognises him as that grey haired man he saw once at the beach and who is vaguely known to him as a pillar of the community. Suppose further that Ralph, being the patriot he is, never turns down the chance to shake hands with those whom he thinks are pillars of the community and would never knowingly shake the hand of any spy and, moreover, that Ortcutt is not a pillar of the community but is in fact a spy. Imagine Ralph sees Ortcutt in the corner and thinks to himself 'That's Bernard J. Ortcutt, pillar of the community, the grey haired man I once saw at the beach. I'm going to go over and shake his hand'. Speaking de dicto, Ralph wants to shake hands with Ortcutt the pillar. We know that Ortcutt is also the man in the brown hat whom Ralph saw skulking suspiciously. Suppose we also think that Ralph is right to think that this guy, whom we know is Ortcutt, is a spy. Then, from our point of view, we might say that, speaking de re, the spy in the corner in such that Ralph wants to shake hands with him. So there is Ralph shaking Ortcutt's hand. What is he up to? Well, he is trying to shake hands with a pillar of the community but what he is actually doing is shaking hands with a spy. What explains the former fact? Why is Ralph trying to shake hands with a pillar of the community? Because he (de dicto) wants to shake hands with a 
pillar of the community. Why, on the other hand, is Ralph the patriot shaking hands with a spy? Well, he (de dicto) wants to shake hands with a pillar of the community and (de re) believes, of a spy, that he is a pillar of the community. The de re attribution is essential. We want to explain why Ralph unintentionally shook the hand of a spy; or less misleadingly, why his attempt to shake a pillar's hand had the consequence that he shook a spy's hand. Since this action of Ralph's was unintentional we will not be able to advert to his way of looking at things, his “notional world" as Dennett (1982) calls it; eo ipso we cannot advert to a de dicto ascription to explain what he in fact did.

To make the same point from a slightly different angle, suppose we want to predict what Ralph will try to do, on the one hand, and what he will in fact do, on the other. Regarding the former, if we think that Ralph (de dicto) wants desperately to shake the hand of a pillar of the community, then it is reasonable to think that Ralph will indeed try to do so. The generalisation at work here is simply the platitude that people try to do what they most want to do when they think it is best for them to do so. If we have reason to think that, speaking de dicto, Ralph thinks that Ortcutt is a pillar of the community then we have reason to predict that he will try to shake Ortcutt's hand. If we are able to specify Ralph's intentions in a way that he would acknowledge as his intentions, we will be able to determine what he is likely to try to do. Suppose, though, we are interested in what Ralph will actually end up doing. As Terence Tomkow (1992) has convincingly argued, following Morton's (1975) lead, Ralph's desire to shake the hand of a pillar of the community will not necessarily help us. For maybe there really is a pillar of the community at the party, the mayor, say. We know that Ralph will try to shake the hand of the pillar. Our question can be put like this: Will he succeed in this endeavour? Suppose the mayor and Ortcutt are over by the bar 
chatting and we see Ralph approaching with his hand out. Whose hand will he shake?

Clearly we need to know which of the two is such that Ralph thinks he the pillar. If it is Ortcutt then we can predict that he will shake Ortcutt's hand. Or perhaps the situation is this. Ralph wants to shake hands with a pillar and believes Ortcutt is a pillar-but it is the mayor that is mistakenly believed by Ralph to be Ortcutt. In this case, we predict that Ralph will shake the mayor's hand. If we are able to specify which object it is that Ralph's intentions are directed upon then we will be able to determine what he is likely to do whether or not that is what he tries to do. In order to explain or predict what Ralph will in fact do we need de re ascriptions; de dicto ascriptions are not sufficient.

\title{
3. Dual-component explanations
}

We can deepen our understanding of the nature of de re action explanation by casting a critical eye over "dual-component" model of psychological explanation found in many internalistically inclined authors. ${ }^{11}$ To take a representative example, Harold

Noonan (1986) argues in favour of the following thesis:

\begin{abstract}
Whenever an action is directed towards a concrete, contingently existing object, other than its agent, in the sense that it is intentional under a description in which there occurs a singular term denoting that object, then an adequate psychological explanation of it is available under a (possibly distinct) description in which occurs a term denoting that object; and in this explanation the only psychological states of the agent referred to are ones which would also be present in a counterfactual situation in which the object did not exist.
\end{abstract}

He adds that:

any defender of thesis $\mathrm{R}$ must maintain that in any explanation of a successful action there must be two components: a purely psychological component in which the relevant attitudes of the agent are cited; and a second, not purely psychological component, in which the surrounding circumstances which ensure the success of the action are described (p. 69)

\footnotetext{
${ }^{11}$ E.g., Baker, 1982; Noonan, 1986, 1991; Segal, 1989; Carruthers, 1987; Blackburn, 1984, ch. 9. Dual-component theories of psychological explanation should not be confused with dual-component theories of mental content or meaning, such as that found in McGinn (1982), though I think it is natural to expect a D-C theorist about content to be a D-C theorist about explanation and vice-versa.
} 
This is the dual-component (D-C) model. The idea is that we can explain an agent's action upon an object by citing purely internal states, that is, states that locally supervene on the agent's body, and adding a statement to the effect that there was an object so situated that the agent made contact with it. ${ }^{12}$

All the aforementioned D-C theorists take themselves to be offering an account of the explanation of intentional action-though Noonan's claim, in the above quotation, about an agent's action, namely, that 'an adequate psychological explanation of it is available under a (possibly distinct) description', is crucially unclear with respect to whether this '(possibly distinct) description' is supposed to be one under which the action is intentional. That the (possibly distinct) description in question is intended to be one under which the action is intentional is evident by the fact that Noonan, Segal (1989), and Carruthers (1987) all take great pains to emphasise that the D-C model of explanation is a form of rationalisation. ${ }^{13}$ After all, both subjects are acting in the sense that they are both trying to do the same type of thing; for example, pick up, or perhaps reach out for, what they take to be a container of pills in front of them which contains the pills they need to live, to use Peacocke's (1981) nice example. If we can rationalise deluded Roxanne's action of reaching out with a set of thought ascriptions, $X$, then $X$ should equally well rationalise non-deluded Roxanne's action of reaching out. To complete the explanation of non-deluded Roxanne's action of reaching out for the container of pills we merely add the fact that the container of pills in question was

\footnotetext{
12 Many philosophers (e.g., Noonan, 1986, 1991; Segal, 1989; Carruthers, 1987; Blackburn, 1984, ch. 9) try to use the model as part of an argument against the existence of the so-called "object-dependent" thoughts of Gareth Evans (1982) and John McDowell (1984, 1986). Object-dependent thoughts are thought whose identity and existence depends on the identity and existence of their objects. The argument against them, briefly, is that reference to object-dependent thoughts is "redundant" in the psychological explanation of intentional action because the D-C model suffices to explain all cases of intentional action upon objects. Since object-dependent thoughts play no essential role in such explanations their very existence is called into question. The argument is criticized in Crawford (1998). ${ }^{13}$ Indeed, the redundancy argument against object-dependent thought (see previous mote) turns essentially on the assumption that a deluded, hallucinating twin of a subject who does not act on any object performs a no less rational action than his non-hallucinating and non-deluded twin who does act on an object; in other words, they both have their reasons for trying to do what they are trying to do.
} 
happily located at the point where she reached out. The first, psychological component of the D-C model applies to both the deluded subject and her non-deluded twin and consists of ascriptions of demonstrative thoughts, such as 'that so-and-so' in the case of Roxanne, 'that container'. The difference comes with the second, not purely psychological component: only in the case of the non-deluded twin is mention made of the fact that an object was so positioned that the subject acted upon it.

Evidently, the D-C theorist's way of explaining a non-deluded subject's action upon an object depends on the stratagem of "breaking up" that explanandum into two components: (a) a statement referring to an action performed by the agent that is a token of a type of action a token of which is also performed by the subject's hallucinating twin, such as reaching out; (b) a statement that the subject's token action bears a certain relation to the object acted upon. Baker (1982) takes the type of action in (a) to be a basic action, where a basic action, $B$, is one where there is no other action $A$ such that an agent performs $B$ by intentionally performing $A$. The example she gives is reaching-and-grasping. Though the other D-C theorists do not pronounce on whether the token action in (a) is always a basic action, their examples all involve what appear to be basic actions. In any event, what all the D-C theorists have apparently failed to notice is that the expressions referring to the objects acted upon in the second not purely psychological component (b), in which the 'surrounding circumstances which ensure the success of the action are described', occur in transparent position, since they fall outside the scope of any of the psychological verbs that occur in the set $X$ of ascriptions of demonstrative thoughts that explain the token of the action type described in the first psychological component of the broken-up explanandum, (a). What this means is that the D-C model has in effect subtlety changed the explanandum from an intentional action, a 
trying, to an action simpliciter, a doing. For the explanandum is no longer the nondeluded subject's reaching out for object $o$ but rather, to put it in questionable English, $o$ 's being reached out for by the subject. Since ' $o$ ' here now takes wide scope, this means we can substitute for it a co-referring expression 'the $\varphi$ ' that the subject is unaware picks out $o$. Thus picked out, the explanandum is no longer the subject's intentional action since he or she may not have intended to act upon the $\varphi$ where 'the $\varphi$ ' denotes $o$. The D-C conception does not therefore provide an adequate model of rationalizing explanations of intentional action.

Let us look at this in more detail. Consider Segal's (1989) schematic account of the D-C procedure. Taking our deluded and non-deluded twin subjects to be, respectively, $S 1$ and $S 2$, and their respective action tokens to be $A 1$ and $A 2$, we can say, according to the D-C account, that $A 1$ and $A 2$ are tokens of the same action type (probably some kind of basic action), the only difference being that $A 2$ happens to have a relational property that $A l$ lacks, namely, bearing a relation to object $o$. Given all this, Segal claims that 'Since $X$ [the set of thoughts in the first, purely psychological component of the explanation and which are shared by $S 1$ and $S 2$ ] explains acts of type $A 1, X$, together with the fact that $o$ is around, will explain $S 2$ 's doing $A 2^{\prime}$ ' (1989, p. 45). As we have just seen, the claim that ' $X$, together with the fact that $\mathrm{o}$ is around will explain $S 2$ 's doing $A 2$ ' depends on the coherence of breaking up $A 2$ into two parts, or, to put is in Segal's terms, that ' $S 2$ 's performance of $A 2$ [is] constituted by her performing an act of the same type as $A 1$, in relation to $o^{\prime}$ (ibid.). It is this last claim that is false and whose falsity undermines the idea that the D-C model of explanation is a model of rationalization.

To see this clearly, we need to work through an example. Let us take Oedipus's kissing Jocasta as $A 2$. The explanandum in question is the intentional action of 
Oedipus's kissing Jocasta. Oedipus intended to kiss Jocasta; that is what he was trying to do, in our jargon. His kissing her is the kind of explanandum for which one gives a rationalising psychological explanation; for since kissing Jocasta is something he intended to do Oedipus has reasons for doing it. Intuitively, these reasons include inter alia his desire, say, to kiss his wife and his belief that Jocasta, or perhaps that women, is his wife. This belief-desire pair explains $A 2$, Oedipus's intentionally kissing Jocasta. The D-C explanation of this begins by breaking up Oedipus's action of kissing Jocasta into a component that says that Oedipus intentionally performed a token of a type of action a token of which Twin-Oedipus, who is hallucinating Jocasta, also performs, such as intentionally puckering his lips, $A 1$, and a component that says that $A l$ is related to Jocasta. Putting the two components together, we see that the explanandum has been transformed from the original intensional statement describing $A 2$, namely, Oedipus intentionally kissed Jocasta, in which the position occupied by 'Jocasta' is not open to substitution of coreferring expressions (it is not true that Oedipus intentionally kissed his mother), to the extensional statement describing Al's relation to $o$, namely, Jocasta was the object of Oedipus's intentional lip-puckering, in which the position occupied by 'Jocasta' is open to substitution. Since the position occupied by 'Jocasta' in the latter is open to substitution, we can substitute 'his mother' and arrive at: his mother was the object of Oedipus's intentional lip-puckering. The very heart of the D-C conception-its dualcomponency - prevents any blocking of this substitution. This shows that, pace Segal, $S 2$ 's performance of $A 2$ is not "constituted by" her performing an act of the same type as $A 1$ in relation to $o$. For, to put it in terms reminiscent of Davidson's (1971a, 1971b) classic discussion of the opacity of attributions of intention, Oedipus intentionally kisses Jocasta but he does not intentionally kiss his mother. The statement 'Jocasta 
was the object of Oedipus's intentional lip-puckering' leaves it open whether he intentionally kissed Jocasta in a way that 'Oedipus intentionally kissed Jocasta' clearly does not.

Moreover, it looks like the advocates of the D-C model not only fail to distinguish between intentional action (trying) and unintentional action (doing) but fail to distinguish between action and non-action. To see this, consider what Lynn Rudder Baker has to say about the application of her D-C model to a famous (fictional) action:

if there had actually been a dagger in front of Macbeth, then Macbeth, having exactly the same attitudes and making exactly the same movements, would have seized it. The difference between Shakespeare's Macbeth and our hypothetical Macbeth is not a matter of Macbeth's attitudes, de re or not. (1982, p. 384)

This cannot be right, as the example of veridical hallucination brings out. Suppose Macbeth is hallucinating a dagger and that, unbeknownst to him, there actually is a dagger qualitatively identical to the one he is hallucinating located in the same egocentric space as the hallucinatory dagger. He tries to clutch the 'fatal vision' and ends up clutching the real dagger. In this rewriting of Shakespeare, Macbeth's clutching the dagger is not an action - for there is no description under which it was intentional. Macbeth did not intend to clutch the dagger under any description since he was not even aware of its existence. It is a pure accident, a coincidence, that he happens to clutch the dagger, as is shown by the truth of the counterfactual that if the dagger had not been there then he still would have tried to clutch the fatal vision by preforming the same basic action. ${ }^{14}$ In such a case, it is precisely a matter of a de re ascription relating Macbeth to the dagger that makes the difference between his clutching it being an action and his clutching it not being an action. Macbeth's

\footnotetext{
${ }^{14}$ Crawford (1998). Cf. Peacocke (1981, 1993) and Morton (1975).
} 
clutching the dagger is an action only if he intended de re, of that dagger, that he clutch it (under some description of it). ${ }^{15}$

The role of the de re ascription comes out clearly when we consider Tyler Burge's (1982) discussion of his example of Alfred and the apples. There is an apple-apple 1 - on the counter in front of Alfred and he thinks it is wholesome; wanting to eat something wholesome, he reaches out and eats the apple. Burge supposes that, counterfactually, it might have been that Alfred was pondering the wholesomeness of an identically appearing yet internally rotten apple and reached out and ate it. Burge is a D-C theorist and according to his theory of singular or de re thought, in the actual and counterfactual situations Alfred would be engaging in contextually different 'applications' (1983) of the same demonstrative mental content to different objects. 'The nature of his mental state is the same', as Burge (1982) puts it, 'he simply bears different relations to his environment' (p. 97). Though to my knowledge Burge nowhere discusses singular psychological explananda, I take it that on his theory, the explanation of why apple 1 got eaten by Alfred would consist in part in saying that Alfred believed, of apple 1, that it was wholesome. This is a de re ascription. As such, it explains what Alfred did, namely, eat apple 1. To explain why Alfred ate apple 2 we say that it was apple 2 that Alfred believed to be wholesome. Apple 2, of course, is rotten. So perhaps we want to know why Alfred, wanting to eat something wholesome, ate that rotten apple, which isn't wholesome. The explanation would be that that rotten apple was believed (de re) by Alfred to be wholesome.

In conclusion, the lesson to be drawn from our scrutiny of the D-C model is that one must be very careful about exactly what kind of explanandum one's theory of

\footnotetext{
15 Noonan (1991) attempts to get around the example of veridical hallucination by appealing to a distinction between accidentally true belief and knowledge. The attempt is countered in Crawford (1998).
} 
psychological explanation is a theory of: is it a trying, a doing or a non-action? There is no reason why D-C theorists cannot acknowledge the difference between tryings, doings and non-actions. And there is no reason why they cannot accept that explanans consisting entirely of purely psychological components (namely, de dicto ascriptions) explain tryings (for example, Oedipus's marring Jocasta); that explanans including not-purely-psychological components (namely, de re ascriptions), explain doings (for example, Alfred's eating of apple 1); and that explanans that include purely nonpsychological components (for example, a statement describing the agent's interaction with an object that is not intentional under any description, as in the case of veridically hallucinating Macbeth) explain non-actions. But in doing so, D-C theorists must accept that the D-C model is an account only of the latter two types of explananda, doings and non-actions. ${ }^{16}$

\footnotetext{
${ }^{16} \mathrm{I}$ am grateful to an anonymous referee for helping me to see more clearly what the implications of my account of de re and de dicto explanation are for the D-C model and also for further comments that prompted significant changes that have resulted in an improvement on the original submission.
} 


\section{References}

Baker, Lynne Rudder. 1982. 'De Re Belief in Action'. Philosophical Review 91: 363-87.

Blackburn, Simon. 1984. Spreading the Word. Oxford: Clarendon Press.

Boghossian, Paul A. 1994. 'The Transparency of Mental Content'. In James Tomberlin, ed., Philosophical Perspectives 8: Logic and Language. Atascadero, CA: Ridgeview Publishing Company.

Brandom, Robert. 1994. Making it Explicit: Reasoning, Representing, and Discursive Commitment. Cambridge, MA: Harvard University Press.

Burge, Tyler. 1977. 'Belief De Re'. Journal of Philosophy 74: 338-62.

- 1982. 'Other Bodies'. In Woodfield.

- 1983. 'Russell's Problem and Intentional Identity'. In James Tomberlin, ed., Agent, Language, and the Structure of the World. Indianapolis: Hackett.

Carruthers, Peter. 1987. 'Russellian Thoughts'. Mind 96: 18-35.

- 1988. 'More Faith than Hope: Russellian Thoughts Attacked'. Analysis 48: 9196.

Crawford, Sean. 1998. 'In Defence of Object-Dependent Thoughts'. Proceedings of the Aristotelian Society 98 (2): 201-210.

Crawford, Sean. 2008. 'Quantifiers and Propositional Attitudes: Quine Revisited', Synthese (2008) 160:75-96

Davidson, Donald. 1971a. 'Agency'. In Robert Binkley, Richard Bronaugh, and Ausonio Marras, eds., Agent, Action, and Reason. Toronto University Press. Reprinted in Davidson (1980).

- 1971b. 'Eternal vs. Ephemeral Events'. Noûs 5 (1971). Reprinted in Davidson (1980).

- 1980. Essays on Actions and Events. Oxford: Clarendon Press.

Dennett, Daniel. 1982. 'Beyond Belief'. In Woodfield.

Evans, Gareth. 1982. The Varieties of Reference. Ed. John McDowell. Oxford: Clarendon Press.

Fiengo, Robert and Robert May. 2006. De Lingua Belief. Cambridge, Mass: MIT 
Press.

Fodor, Jerry. 1980. 'Methodological Solipsism Considered as a Research Strategy in Cognitive Psychology'. The Behavioural and Brain Sciences 3.

Forbes, Graeme. 1996. 'Substitutivity and the Coherence of Quantifying In'. Philosophical Review 105: 337-72.

Kripke, Saul. 1979: 'A Puzzle about Belief'. In A. Margalit, ed., Meaning and Use. Dordretch: Reidel.

Loar, Brian. 1972. 'Reference and Propositional Attitudes'. Philosophical Review 80.

Lycan, William. 1985. 'Thoughts about Things'. In Miles Brand and R.M. Harnish, eds. The Representation of Knowledge and Belief Tucson: University of Arizona Press.

McDowell, John. 1984. 'De Re Senses'. Philosophical Quarterly 34: 283-94.

- 1986. 'Singular Thought and the Extent of Inner Space'. In Philip Pettit and John McDowell, eds. Subject, Thought and Context. Oxford: Clarendon Press.

McGinn, Colin. 1982. 'The Structure of Content'. In Woodfield.

Morton, Adam. 1975. 'Because He Thought He Had Insulted Him'. Journal of Philosophy 62: 5-15.

Noonan, Harold. 1986. 'Russellian Thoughts and Methodological Solipsism'. In Jeremy Butterfield, ed., Language, Mind, and Logic. Cambridge: Cambridge University Press.

- 1991. 'Object-Dependent Thoughts and Psychological Redundancy'. Analysis 51

Peacocke, Christopher. 1981. 'Demonstrative Thought and Psychological Explanation'. Synthese 49: 187-217.

- 1993. Externalist Explanation. Proceedings of the Aristotelian Society 93: 20330.

Quine, W. V. 1956. 'Quantifiers and Propositional Attitudes'. In Quine (1966).

- 1960. Word and Object. Cambridge, MA: MIT Press.

- 1966. The Ways of Paradox and Other Essays. New York: Random House.

- 1977. 'Intensions Revisited'. In Peter A. French, Theodore E. Uehling, Jr., and Howard K. Wettstein, eds., Contemporary Perspectives in the Philosophy of Language. Minneapolis: University of Minnesota Press. 
- 1986a. Reply to David Kaplan. In Hanh \& Schilpp (eds.) The Philosophy of W. V. Quine. La Salle, Illinois: Open Court, 1986.

- 1986b. Philosophy of Logic. 2nd ed. Cambridge, MA: Harvard University Press.

Russell, Bertrand. 1910. 'On the Nature of Truth and Falsehood'. Philosophical Essays. London: Allen and Unwin.

Schiffer, Stephen. 1978. 'The Basis of Reference'. Erkenntnis 13.

- 1990. 'The Mode of Presentation Problem', in C. Anthony Anderson and Joseph Owens, eds., Propositional Attitudes. CSLI: Stanford.

Segal, Gabriel. 1989. 'The Return of the Individual'. Mind 98: 39-57.

Tomkow, Terrance. 1992. Against Representation. MS.

Wallace, John. 1972. 'Belief and Satisfaction', Nous 6.

Woodfield, Andrew, ed. 1982. Thought and Object. Oxford: Clarendon Press. 